Full paper prepared for:

8th International Conference on Management in AgriFood Chains and Networks

\title{
Supply chain performance measurement: The case of the traditional food sector in the $\mathrm{EU}$
}

\author{
Xavier Gellynck $^{1}$, Adrienn Molnár ${ }^{1}$ and Lusine Aramyan ${ }^{2}$
}

${ }^{1}$ Ghent University, Faculty of Bioscience Engineering, Department of Agricultural Economics, Division Agro-Food Marketing Coupure Links 653, B-9000 Ghent, Belgium

Tel: +32926459 46, Fax: +3292646246

${ }^{2}$ Agricultural Economics Research Institute (LEI)

P.O.Box 2970, 2502 LS The Hague, The Netherlands

Tel: +31(0)70-3358137, Fax: +31(0)70-3358196

*Corresponding author, E-mail: Adrienn.Molnar@Ugent.be

\begin{abstract}
The objective of this study is to develop a sound measurement instrument of traditional food supply chain performance integrating the perspectives of different stakeholders. Therefore first, stakeholders' goals are generalized via focus groups and individual interviews. Second, stakeholders' goals are consolidated, based on their specificity and conflicting/divergent nature and as a result, supply chain goals are developed. Third, potential performance indicators are listed, supporting the developed supply chain goals. Fourth, key performance indicators (KPIs) are selected. As a result, five main supply chain goals are formulated (traditionalism, efficiency, responsiveness, quality and chain balance) together with their supporting performance indicators. Future research should focus on validating the instrument in both other food and nonfood sectors.
\end{abstract}

Keywords: traditional food supply chain, performance measurement instrument, stakeholders' perspective 


\section{Introduction and objectives}

Organizations nowadays no longer compete as independent entities, but as supply chains (Christopher, 1998, Cox, 1999, Lambert and Cooper, 2000), therefore they more and more realize the performance potential of supply chains (Pearson and Samali, 2005, Gellynck et al., 2006). Being part of a well-performing supply chain generates important performance benefits for the individual organization. As a result, there is increasing interest of the performance of supply chains as a whole (Beamon, 1998a).

An adequate supply chain performance measurement instrument should identify how well the supply chain is performing, draw attention to where improvements are possible, facilitate detecting problems and choose where to focus on (Cohen and Roussel, 2005). Consequently, it affects decision making through the assessment of past actions and through benchmarking (Aramyan, 2007). Further, it can assist the distribution of resources, measure and communicate improvement towards strategic goals and assess managerial practices (Ittner and Larcker, 2003). In addition, it helps managers to recognize good performance, to make tradeoffs between profit and investments, it provides ways to set strategic targets and enables managers to get involved if performance is distracting (Neely et al., 1995).

Contrary to the raising awareness of the performance potentials of supply chains, simultaneous development of supply chain performance measurement instruments didn't follow (Gunasekaran et al., 2001). As a result and in spite of its necessity, a vast group of authors (Neely et al., 1994, Neely et al., 1995, Beamon, 1998b, Christopher, 1998, Beamon, 1999, Li and O'Brien, 1999, Van der Vorst, 2000, Gunasekaran et al., 2001, Lambert and Pohlen, 2001, Gunasekaran et al., 2004, Van Der Vorst, 2006) agrees that there are still key issues to be addressed when developing supply chain performance measurement instruments. For instance, despite the great necessity of excellent supply chain performance measurement instruments, the existing ones often show weaknesses in terms of universality (allow for comparison under various circumstances) (Beamon, 1996b), therefore they are not generally applicable (Neely et al., 1995). Further, there is a need for performance measurement instruments that assess the performance across the whole supply chain (Lambert and Pohlen, 2001). Finally, however most of the supply chain performance measurement instruments indicate how successfully supply chain function; they do not explore a complex bundle of goals (supply chain goals) for which those supply chains (should) function. Since performance can be generally defined as the level of achievement of goals (Kaplan, 1983, Ittner and Larcker, 2003), analyses of supply chain performance remains incomplete because they do not measure the level of achievement of all the supply chain goals.

Moreover, with regard to measuring performance of supply chains active in the agri-business sector in general and in the traditional food sector in particular, literature points a number of additional problems over the already mentioned ones (Aramyan, 2007). First, many agri-food firms, including traditional food firms do not screen their performance in a regular way (Collins et al., 2001). Second, supply chains belonging to different sectors may have different characteristics (e.g. supply chain length, the closeness of supply chain relationships, types of process links) (Lambert and Cooper, 2000), which may influence the performance assessment process. Consequently performance measurement instruments being developed for other sectors do not always fit for traditional food supply chains. Concluding, research on measuring performance of traditional food supply chains received little attention in literature (Jordana, 2000, Theodoras et al., 2005, Trichopoulou et al., 2006, Aramyan, 2007). In addition, a notable exception of the existing measurement instruments integrates the perspectives of different 
stakeholders of traditional food supply chains, such as suppliers, focal companies and customers (Aramyan, 2007). This is the rationale of our study being designed to fill these gaps by developing a supply chain performance measurement instrument tailored to the traditional food sector that integrates the opinion of different stakeholders. We aim to add to the supply chain management literature by enriching the current state of art and by developing a novel supply chain performance measurement instrument.

Consequently, the objective of this study is to develop a sound measurement instrument of traditional food supply chain performance integrating the perspectives of different stakeholders.

This paper is structured as follows: In the following part the methodology of the paper is presented. Next, the research results are discussed and finally conclusions are drawn as well as further research topics formulated.

\section{Methodology}

The above aim is addressed via a four-stage process: 1) Generalization of stakeholders' goals, 2) Consolidation of stakeholders' goals, 3) Selection of potential performance indicators supporting supply chain goals, 4) Selection of key performance indicators (KPIs). This four-stage process is developed by adapting methodologies used by Hines (2000), Aramyan (2007) and Young et al. (2004) and is particularly suitable for developing supply chain performance measurement instruments based on supply chain goals.

\subsection{Generalization of stakeholders' goals (Stage 1)}

For the generalization of the stakeholders' goals focus groups and individual interviews have been conducted with stakeholders (suppliers, focal companies and customers) of traditional food supply chains from three European countries (Belgium, Italy and Hungary), representing five different traditional food product categories (cheese, beer, dry ham, dry sausage and white pepper). Details about the composition of each focus group and individual interview are provided in Annex 1. Based on a topic list, stakeholders of traditional food supply chains have been invited to express their business goals (Hines et al., 2000). The identification of these goals enable later the precise selection of potential performance indicators supporting these goals (Walsh, 1996, Roos and Jacobsen, 1999).

\subsection{Consolidation of stakeholders' goals (Stage 2)}

In the second stage of the process, the different goals of stakeholders are consolidated. The consolidation process consists of evaluating the stakeholders' goals based on their specificity (country or product) and their conflicting/divergent nature.

Specificity is one the main shortcomings of existing supply chain performance measurement instruments as a result of too specific stakeholder goals. Existing supply chain performance measurement instruments often present significant weaknesses in terms of universality (allow for comparison under various conditions) (Beamon, 1996a), therefore they are not generally applicable (Neely et al., 1995). As a result, they are highly tailored to the characteristics of a given country or product category. Our methodology is developed to overcome this problem. In order to build up a highly robust and accurate supply chain performance measurement instrument, which is suitable for comparison, country and product specific goals need to be eliminated. Therefore, goals only being mentioned in one of the participating countries are removed as well as those only being mentioned by the stakeholders of one product category (cheese, beer, dry ham, dry sausage or white pepper). 
Another important obstacle of consolidation of stakeholders' goals is the lack of goal consensus between the different stakeholders (Van De Ven, 1976) because of the conflicting or divergent nature of stakeholders' goals (Lee and Billington, 1999). As a result, stakeholders' goals are often not applicable for the entire supply chain (Aramyan, 2007). In line with the methodologies used by Aramyan (2007) and Young (2004), goals are removed if only one group of stakeholders (Aramyan, 2007) (suppliers, focal companies or customers) endorsed them. In this way, goals being approved by several stakeholders of the supply chain are obtained, so called supply chain goals.

\subsection{Selection of potential performance indicators supporting supply chain goals (Stage 3)}

In the third-stage of the process, the literature is reviewed to identify potential performance indicators which allow the measurement of progress towards the supply chain goals (Walsh, 1996, Hines et al., 2000). While the different supply chain goals are rather general, the selected performance indicators are more concrete and measurable (Roos and Jacobsen, 1999). Further, the different supply chain goals hardly ever include only one performance indicators but they usually imply several. For example, the goal "to maintain superior quality" can be measured in many different ways, such as taste, health, safety, attractiveness or environmental friendliness (Beamon, 1999, Aramyan, 2007). Similarly, the goal "to increase efficiency" can be measured by different performance indicators, such as distribution cost, transaction cost, profit or inventory cost (Neely et al., 1995, Beamon, 1999, Van der Vorst, 2000). Therefore, each supply chain goal can be linked to several potential performance indicators.

\subsection{Selection of key performance indicators (Stage 4)}

The output of the third-stage is a list of performance indicators supporting the different supply chain goals. In order to select the most appropriate performance indicators (key performance indicators, KPIs) related to each supply chain goal, a questionnaire has been compiled and pilot tested in the fourth stage of the process. The pilot study has been carried out in eight traditional food supply chains originating from three European countries (Belgium, Italy and Hungary) and representing three product categories (beer, cheese and dry sausage respectively). Face-to-face interviews with minimum three members per supply chain (suppliers, focal companies and customers) have been conducted in September 2007. Details about the interviews are provided in Annex 2. During the pilot study, respondents have been asked to score the importance of each performance indicator for their company, using a seven-point response scale ranging from strongly unimportant (1) to strongly important (7). This helps to remove performance indicators that are appropriate but may not be as suitable as other related performance indicators. For example selecting between "distribution cost", "transaction cost", "profit" and "inventory cost" might be difficult, since they are all informative about efficiency, but each provide different information. Using the importance scores, the stakeholders can identify which of these performance indicators are most appropriate (Keeble et al., 2003). Further, to arrive at a robust supply chain performance measurement instrument comprising a minimal set KPIs (Dransfield et al., 1999), the following steps are undertaken during the analysis: First, given the appropriate level of internal consistency of the sets of performance indicators (hereafter called supply chain goals) (Brosius, 2002), the importance scores for the different supply chain goals are calculated. Second, the supply chain goals with the lowest importance scores are removed from the final questionnaire. Third, at the level of the remaining supply chain goals, 
performance indicators scoring below average are marked as "under consideration for being eliminated" and further analyzed. Fourth, significant differences among the different stakeholder groups (suppliers, focal companies and customers) and among the different countries (Belgium, Italy and Hungary) are investigated, and fifth, the descriptive comments of the respondents are analyzed. The actual elimination of these performance indicators depend on these last two steps. As a result of the above procedure, the key performance indicators to measure progress towards supply chain goals become clear and unambiguous. In this way an appropriate supply chain performance measurement instrument is obtained.

\section{Results}

The results are discussed by following the different stages as explained above under the methodology. First, the generalization and consolidation of stakeholders' goals are presented. Next, potential performance indicators are identified and finally the selection of key performance indicators is discussed.

\subsection{Generalization and consolidation of stakeholders' goals (Stage} 1\&2)

During focus groups and individual interviews, 275 goals of stakeholders are generalized. These goals are now consolidated based on their specificity (country or product) and their conflicting/divergent nature.

\section{Goal specificity:}

Differences with regard to stakeholders' goals can be distinguished between respondents representing different product categories or originating from different countries.

First, the product-related differences are discussed. Some respondents, especially the ones producing/distributing seasonal products (e.g. white pepper), express their concern about "handling seasonality", "being more flexible in reacting on demand fluctuations", "starting up a greenhouse to avoid off-peak periods", "intensify postharvest activities" or "increase irrigated areas" as important goals. This is in line with findings of Felföldi (2007) analyzing the characteristics of vegetable supply chains. Contrary to this, respondents representing nonseasonal products (e.g. beer, cheese) do not mention the above issues. Further, for instance stakeholders belonging to the cheese or ham supply chains aim to "focus marketing efforts on the healthy character of the product", while stakeholders of beer supply chains do not consider this as being important, since legal restrictions do not allow the promotion of health claims of beers (Hasler, 2002). "Better fight with diseases" and "lower mortality rate" are typical goals of dry ham and dry sausage stakeholders, while "reduced milk fever occurrences and clinical mastitis" are typical for cheese supply chain stakeholders. Finally, "decrease drought and salinity risk" can be associated with white pepper and beer supply chains because of the nature of the raw materials.

Second, country-related differences are presented. Basic differences can be drawn between the new member state (Hungary) and the two others (Belgium and Italy). Hungarian respondents often struggle with "missing markets", "bad influence of government failures on food consumption", "small-scale farming", "lack of information at sector and producer level" or "low technological level" as indicated in the literature (Felföldi, 2007). As a result, they formulate goals aiming to solve these problems. Further, in Belgium, stakeholders typically display the 
"assurance of future continuous supply of raw materials" as one of their main goals, which can be explained by the lack of raw materials because of the lack of available agricultural land and the increasing competition for land between food, feed and bio-energy production (Yamamoto et al., 2001). Another highly displayed goal of the Belgian stakeholders compared to the others is "to build awareness and recognition of the products", and "to cope with the competition from neighboring countries". The frequent allusion of these goals in Belgium compared to the other countries can be explained for instance by the strong presence of French cheeses near at hand, the high consumption of French cheeses in Belgium, and the extremely low recognition of this traditional specialty. Finally, Italian respondents more often claim to "acquire PDO-PGI certifications" than other countries' respondents, which can be explained by the already high proportion of PDO-PGI products and the market success of them (Giraud, 2002).

\section{Conflicting/divergent goals:}

With regard to the stakeholders' goals, the position of Lee and Billington (1999) is confirmed, indicating that supply chains are characterized by conflicting/divergent goals of stakeholders. For instance, "getting higher prices for the products" is observed as an important goal of the suppliers, while "lowering cost of raw materials" is pointed to be an important goal of the focal companies. Further, while "increasing time of payment" is displayed by the customers as a goal, focal companies aim to "receive payment for the products as soon as possible".

Further, even when the goals indicated by the stakeholders are not conflicting, stakeholders often have divergent goals, which derive from the different role of the different groups of stakeholders in the supply chain. For instance, "maintaining the traditional production process", "using the same authentic raw materials", "decreasing production cost" or "lowering finished good stock" as a goal are typically mentioned by the focal companies, but not by the suppliers or the customers. Further, "improving display and presentation" or "providing proper storage conditions" as goals are particularly displayed by customers, but not by focal companies or suppliers. Finally, suppliers aim to "invest into greenhouses for avoiding seasonal fluctuation in supply" (white pepper farmers), "better fight with diseases" (pig producers), "decrease drought and salinity risk" (white pepper farmers) or "reduce milk fever occurrences and clinical mastitis" (milk suppliers).

During the consolidation process, 46 country specific, 37 product specific and 86 divergent/conflicting goals are removed. The retaining goals are group based on their similarity and as a result, seven supply chain goals are formulated. These are the following: growth, traditionalism, efficiency, flexibility, responsiveness, quality and chain balance.

\subsection{Selection of potential performance indicators supporting supply chain goals (Stage 3)}

In the third-stage of the process, the literature is reviewed to identify potential performance indicators which allow the measurement of progress towards the seven supply chain goals (Walsh, 1996, Hines et al., 2000) (Table 1). First, four performance indicators may measure the achievement of the supply chain goal "growth" : market share growth, product assortment growth, local market growth/new local market, international market growth/new international market (Claro et al., 2003, Chen and Paulraj, 2004). Second, four performance indicators may measure the achievement of the supply chain goal "traditionalism", namely locality, authenticity, commercial availability and gastronomic heritage. Locality contains two items. The first indicates that the key production steps are carried out in a recognizable national, regional or 
local area. The second refers to the requirements that key stakeholders of the traditional food supply chains are primarily active in a recognizable national, regional or local area. Authenticity is divided into three items, namely recipe authenticity, raw material authenticity and production process authenticity. Commercial availability indicates the time interval for which the traditional food product is commercially available. Last, gastronomic heritage refers to the existence of a unique and memorable gastronomic identity of the food product (Fox, 2007). Third, performance indicators of distribution cost, transaction cost, profit and inventory cost can be used to measure the achievement of the supply chain goal "efficiency" (Neely et al., 1995, Beamon, 1998a) (Neely et al., 1995, Beamon, 1998b, Beamon, 1999, Van der Vorst, 2000, Aramyan, 2007).

Table 1: Potential performance indicators supporting supply chain goals

\begin{tabular}{|l|l|}
\hline Growth & Responsiveness \\
\hline Market share growth & Fill rate \\
\hline Product assortement growth & Lead time \\
\hline Local market growth & Customer complaints \\
\hline International market growth & Quality \\
\hline Traditionalism & Taste \\
\hline Locality & Health \\
\hline Key production steps & Safety \\
\hline Key stakeholders & Attractiveness \\
\hline Authenticity & Environmental friendliness \\
\hline Recipe authenticity & Chain balance \\
\hline Raw material authenticity & Distribution of risks and benefits \\
\hline Production process authenticity & Information exchange \\
\hline Commercial availability & Chain understanding \\
\hline Gastronomic heritage & \\
\hline Efficiency & \\
\hline Distribution cost & \\
\hline Transaction cost & \\
\hline Profit & \\
\hline Inventory cost & \\
\hline Flexibility & \\
\hline Delivery flexibility & \\
\hline Response to demand variations & \\
\hline Response to new competitors & \\
\hline Response to customer requirement & \\
\hline Anted & \\
\hline
\end{tabular}

Adapted from: (Bensaou and Venkatraman, 1995, Neely et al., 1995, Beamon, 1998b, Beamon, 1999, Bowersox et al., 2000, Van der Vorst, 2000, Akkermans et al., 2003, Claro et al., 2003, Chen and Paulraj, 2004, Aramyan, 2007, Fox, 2007)

Fourth, delivery flexibility, response to demand variations (such as seasonality), response to new competitors and response to customer requirement can be linked to the supply chain goal "flexibility" (Neely et al., 1995, Beamon, 1998b, Beamon, 1999, Van der Vorst, 2000, Aramyan, 2007). Fifth, supply chain goal "responsiveness" are translated into performance indicators of fill rate (Beamon, 1998b, Aramyan, 2007), lead time (Beamon, 1998b, Van der Vorst, 2000, Aramyan, 2007) and customer complaints (Aramyan, 2007). Sixth, the achievement of the supply chain goal "quality" can be measured by taste, health, safety, attractiveness and environmental friendliness based on Chen and Paulraj (2004), Aramyan (2007), Van der Vorst (2000) and Neely (1995). Seventh, the achievement of the supply chain goal "chain-balance" can be measured by distribution of risk and benefits, information exchange and chain understanding based on former research results, such as Bensaou and Venkatraman (1995), Akkermans et al. (2003) or Bowersox (2000). 


\subsection{Selection of key performance indicators (KPIs) (Stage 4)}

Pilot test has been carried out to select the most appropriate performance indicators (KPIs) related to each supply chain goal.

Table 2: Importance of supply chain goals and their performance indicators for the different stakeholder groups; mean scores and standard deviations

\begin{tabular}{|c|c|c|c|c|}
\hline & Suppliers n=9 & Focal companies $n=8$ & Customers n=9 & Sample \\
\hline Importance $^{1}$ & Mean (SD) & Mean (SD) & Mean (SD) & Mean (SD) \\
\hline Growth $^{2}$ & $4,94(1,81)$ & $5,41(1,38)$ & $4,79(0,70)$ & $5,05(1,38)$ \\
\hline Market share growth & $5,11(1,83)$ & $5,50(1,69)$ & $5,57(1,81)$ & $5,38(1,71)$ \\
\hline Product assortement growth & $5,33(2,18)$ & $5,50(1,51)$ & $5,75(1,28)$ & $5,52(1,66)$ \\
\hline Local market growth & $4,89(2,20)$ & $5,63(1,06)$ & $5,75(1,16)$ & $5,40(1,58)$ \\
\hline International market growth & $4,44 a, b(2,79)$ & $5,00 \mathrm{~b}(2,27)$ & $2,50 \mathrm{a}(1,31)$ & $4,00(2,40)$ \\
\hline Traditionalism & $4,56(1,49)$ & $5,63(0,78)$ & $5,56(1,19)$ & $5,22(1,26)$ \\
\hline Locality $^{3}$ & $3,89(2,20)$ & $5,88(1,64)$ & $5,50(1,20)$ & $5,04(1,90)$ \\
\hline Authenticity & $4,67 \mathrm{a}(1,87)$ & $6,25 \mathrm{~b}(0,89)$ & $6,00 \mathrm{a}, \mathrm{b}(1,41)$ & $5,60(1,58)$ \\
\hline Commercial available $^{3}$ & $5,11(1,90)$ & $4,88(1,73)$ & $5,00(1,51)$ & $5,00(1,66)$ \\
\hline Gastronomic heritage & $4,56(1,59)$ & $5,50(1,41)$ & $5,75(1,75)$ & $5,24(1,61)$ \\
\hline Efficiency & $4,44 a(1,04)$ & $5,34 a, b(1,10)$ & $5,84 b(0,87)$ & $5,21(1,13)$ \\
\hline Distribution cost & $4,50 \mathrm{a}(1,85)$ & $4,88 \mathrm{a}, \mathrm{b}(1,96)$ & $6,38 b(1,06)$ & $5,25(1,80)$ \\
\hline Transaction $\operatorname{cost}^{3}$ & $4,89(1,76)$ & $5,13(1,96)$ & $5,00(1,93)$ & $5,00(1,80)$ \\
\hline Profit & $4,67 \mathrm{a}(2,06)$ & $6,25 b(1,75)$ & $6,38 b(0,74)$ & $5,72(1,77)$ \\
\hline Inventory cost ${ }^{3}$ & $3,11 \mathrm{a}(1,27)$ & $5,13 \mathrm{~b}(1,36)$ & $5,63 \mathrm{~b}(1,69)$ & $4,56(1,78)$ \\
\hline Flexibility $^{2}$ & 4,08a $(1,49)$ & 5,03a,b $(1,24)$ & $5,88 \mathrm{~b}(0,73)$ & $4,96(1,38)$ \\
\hline Delivery flexibility & $4,56(1,81)$ & $5,13(2,03)$ & $5,63(1,77)$ & $5,08(1,85)$ \\
\hline Response to demand variations & $3,33(2,12)$ & $5,00(1,51)$ & $5,38(1,51)$ & $4,52(1,92)$ \\
\hline Response to new competitors & $3,89 \mathrm{a}(2,26)$ & $4,63 a, b(2,26)$ & $6,25 \mathrm{~b}(1,04)$ & $4,88(2,13)$ \\
\hline Response to customer requirements & $4,56 \mathrm{a}(1,94)$ & $5,38 \mathrm{a}, \mathrm{b}(2,00)$ & $6,25 b(1,04)$ & $5,36(1,80)$ \\
\hline Responsiveness & $4,37 \mathrm{a}(1,90)$ & $6,04 b(0,84)$ & 5,42a,b $(0,77)$ & $5,24(1,45)$ \\
\hline Fill rate ${ }^{3}$ & $4,33 \mathrm{a}(1,80)$ & $6,38 b(0,52)$ & $3,88 \mathrm{a}(1,73)$ & $4,84(1,80)$ \\
\hline Lead time & $3,89(2,62)$ & $5,25(1,75)$ & $6,00(1,07)$ & $5,00(2,08)$ \\
\hline Customer complaints & $4,89(2,52)$ & $6,50(0,53)$ & $6,38(0,52)$ & $5,88(1,69)$ \\
\hline Quality & $5,48 \mathbf{a}(1,27)$ & 6,53b $(0,33)$ & $6,23 a, b(0,59)$ & $6,02(0,97)$ \\
\hline Taste $^{3}$ & $4,75(1,83)$ & $5,88(1,36)$ & $6,13(0,35)$ & $5,58(1,41)$ \\
\hline Health $^{3}$ & $5,25(1,49)$ & $6,67(0,52)$ & $5,67(1,86)$ & $5,80(1,47)$ \\
\hline Safety & $6,50(0,76)$ & $6,57(0,79)$ & $6,63(0,52)$ & $6,57(0,66)$ \\
\hline Attractiveness & $5,00 \mathrm{a}(1,93)$ & $6,63 b(0,52)$ & $6,50 \mathrm{~b}(0,53)$ & $6,04(1,37)$ \\
\hline Environmental friendliness & $5,88(2,10)$ & $5,71(1,70)$ & $5,88(1,13)$ & $5,83(1,61)$ \\
\hline Chain balance & $4,81(1,63)$ & $5,38(1,39)$ & $5,67(0,90)$ & $5,25(1,36)$ \\
\hline Distribution of risks and benefits & $4,78(1,92)$ & $5,75(1,04)$ & $5,75(1,16)$ & $5,40(1,47)$ \\
\hline Information exchange ${ }^{3}$ & $4,78(1,64)$ & $5,00(1,85)$ & $5,63(1,60)$ & $5,12(1,67)$ \\
\hline Chain understanding & $4,89(1,76)$ & $5,38(2,00)$ & $5,57(1,27)$ & $5,25(1,67)$ \\
\hline
\end{tabular}

${ }^{1}$ Seven-point Likert scale: 1 = strongly unimportant; 2 = moderately unimportant; 3 = slightly unimportant; $4=$ neutral; 5 = slightly important; 6 = moderately important; $7=$ strongly important; different letters $(\mathrm{a}-\mathrm{b}-\mathrm{c})$ indicate significantly different average scores using Mann-Whitney U test

${ }^{2}$ Supply chain goals eliminated because of low average importance scores

${ }^{3}$ Performance indicators marked as "under consideration for being eliminated"

First, given the appropriate Cronbach's values for the supply chain goals, average scores are calculated in Table 2 and 3. Respondents attach relatively high importance to all supply chain goals, confirming the findings of the qualitative research. However, growth and flexibility received moderately lower importance scores. These two supply chain goals are eliminated. At the level of the remaining supply chain goals, further performance indicators are marked as 
"under consideration for being eliminated" because of below-average importance scores, such as locality (traditionalism), commercial availability (traditionalism), transaction cost (efficiency), inventory cost (efficiency), fill rate (responsiveness), taste (quality), health (quality) and information exchange (chain balance).

Traditionalism: Two performance indicators are estimated being of medium importance. One is locality and the other is commercial availability. With regard to locality, no significant difference is found either among the different groups of stakeholders or among the different countries. The final removal of the performance indicator is based on the descriptive comments of the respondents. First of all, in case of food production, outsourcing of specific processes to other companies or even to other countries is very common (Gerbens-Leenes et al., 2003). Locality is therefore not squarely related to traditionalism. If some production steps can not be performed at a given geographic area, this fact can jeopardize the survival of the traditional food producers (Ho, 2005). Further, some stakeholders of traditional food supply chains, especially the bigger raw material suppliers often act on an international market. Therefore, though these raw material suppliers are not exclusively active within a given geographic area, this could exclude them of being traditional. Commercial availability indicates the time interval for which the traditional food product is commercially available. Significant differences are found between Belgium and the other countries. Italian and Hungarian respondents mention to fear that, stressing too much the time interval of the commercial availability could serve as a mean of justification of traditionalism, while the focus should be rather placed on specific product qualities. This is in line with present dissents about the time-length of the tradition. Time interval is part of a product's local history and differs accordingly. It can even differ significantly without becoming a discriminating factor (Bérard and Marchenay, 2007). Therefore commercial availability has been eliminated from the goal traditionalism.

Efficiency: Two performance indicators are considered being of low importance, namely transaction cost and inventory cost. Transaction cost refers to costs other than the money price that are incurred in trading goods or services (e.g. searching cost, negotiation cost, and enforcement cost) (Williamson, 1981). Inventory cost refers to the cost of a firm's merchandise, raw materials, and finished or unfinished products which have not yet been sold (Aramyan, 2007). The importance of the transaction cost item significantly differs between Italy and the other two countries, while the importance of the inventory cost item significantly differs both between Hungary and Italy and between the suppliers and the other two stakeholder groups (customers and focal companies). Previous research (Aramyan, 2007) identifies the same low importance of the above mentioned performance indicators. Therefore transaction cost and inventory cost are removed from the goal efficiency.

Responsiveness: The score for fill rate is rather low and moreover significantly different between the focal companies and the other two categories of respondents (customers and suppliers). Fill rate refers to the percentage of units ordered that are shipped on a given order (Beamon, 1999, Aramyan, 2007). The scientific literature illustrates similar results with high importance for the focal companies and less importance for other supply chain stakeholders (Lambert and Cooper, 2000, Aramyan, 2007). This can be explained by the fact that performing well in terms of fill rate requires from the focal company the integration of manufacturing, distribution and transportation plans, as well as integration of suppliers and customers (Lambert and Cooper, 2000). From the position of the focal companies (being situated between the suppliers and the customers in the supply chain) the recognition of this high importance can be explained. 
Table 3: Importance of supply chain goals and their performance indicators for the different countries, mean scores and standard deviations

\begin{tabular}{|c|c|c|c|c|}
\hline & Belgium $n=9$ & Hungary $n=10$ & Italy $=\mathrm{n} ? ?$ & Sample \\
\hline Importance $^{1}$ & Mean (SD) & Mean (SD) & Mean (SD) & Mean (SD) \\
\hline Growth $^{2}$ & $5,69 \mathrm{~b}(0,92)$ & 5,08a,b $(1,25)$ & $3,85 a(1,76)$ & $5,05(1,38)$ \\
\hline Market share growth & $6,33 b(1,12)$ & $5,70 \mathrm{~b}(0,95)$ & $3,00 \mathrm{a}(1,73)$ & $5,38(1,71)$ \\
\hline Product assortement growth & $5,89(1,27)$ & $5,00(1,83)$ & $5,83(1,94)$ & $5,52(1,66)$ \\
\hline Local market growth & $5,78(1,30)$ & $5,50(0,97)$ & $4,67(2,58)$ & $5,40(1,58)$ \\
\hline International market growth & $4,78(1,99)$ & $4,10(2,64)$ & $2,67(2,34)$ & $4,00(2,40)$ \\
\hline Traditionalism & $5,47(1,49)$ & $5,13(0,52)$ & $5,00(1,85)$ & $5,22(1,26)$ \\
\hline Locality $^{3}$ & $5,78(1,39)$ & $4,90(1,20)$ & $4,17(3,13)$ & $5,04(1,90)$ \\
\hline Authenticity & $5,22(1,72)$ & $5,80(0,79)$ & $5,83(2,40)$ & $5,60(1,58)$ \\
\hline Commercial available ${ }^{3}$ & $6,11 b(1,54)$ & $4,60 \mathrm{a}(1,43)$ & $4,00 \mathrm{a}(1,41)$ & $5,00(1,66)$ \\
\hline Gastronomic heritage & $4,78 \mathrm{a}, \mathrm{b}(2,05)$ & $5,20 \mathrm{a}(0,63)$ & $6,00 \mathrm{~b}(2,00)$ & $5,24(1,61)$ \\
\hline Efficiency & $5,53(1,07)$ & $5,18(1,04)$ & $4,83(1,41)$ & $5,21(1,13)$ \\
\hline Distribution cost & $4,50(2,14)$ & $5,20(1,62)$ & $6,33(1,21)$ & $5,25(1,80)$ \\
\hline Transaction cost ${ }^{3}$ & $5,56 \mathrm{~b}(1,01)$ & $5,80 \mathrm{~b}(1,03)$ & $2,83 \mathrm{a}(2,14)$ & $5,00(1,80)$ \\
\hline Profit & $6,11(1,62)$ & $6,10(0,99)$ & $4,50(2,59)$ & $5,72(1,77)$ \\
\hline Inventory cost ${ }^{3}$ & $4,89 a, b(1,90)$ & $3,60 \mathrm{a}(1,43)$ & $5,67 \mathrm{~b}(1,51)$ & $4,56(1,78)$ \\
\hline Flexibility $^{2}$ & $4,86(1,13)$ & $4,98(1,43)$ & $5,08(1,86)$ & $4,96(1,38)$ \\
\hline Delivery flexibility & $4,89(1,90)$ & $4,60(1,96)$ & $6,17(1,33)$ & $5,08(1,85)$ \\
\hline Response to demand variations & $5,33 b(0,87)$ & $3,90 \mathrm{a}(1,79)$ & $4,33 \mathrm{a}, \mathrm{b}(2,94)$ & $4,52(1,92)$ \\
\hline Response to new competitors & $4,78(2,11)$ & $5,70(1,42)$ & $3,67(2,80)$ & $4,88(2,13)$ \\
\hline Response to customer requirements & $4,44 \mathrm{a}(1,74)$ & $5,70 \mathrm{a}, \mathrm{b}(1,89)$ & $6,17 b(1,33)$ & $5,36(1,80)$ \\
\hline Responsiveness & $5,33(0,88)$ & 4,73 (1,99) & $5,94(0,74)$ & $5,24(1,45)$ \\
\hline Fill rate ${ }^{3}$ & $5,67(0,71)$ & $4,60(2,12)$ & $4,00(2,10)$ & $4,84(1,80)$ \\
\hline Lead time & $4,22 \mathrm{a}(2,05)$ & $4,50 \mathrm{a}(2,07)$ & $7,00 \mathrm{~b}(0,00)$ & $5,00(2,08)$ \\
\hline Customer complaints & $6,11(0,93)$ & $5,10(2,33)$ & $6,83(0,41)$ & $5,88(1,69)$ \\
\hline Quality & $5,95(0,60)$ & $5,78(1,23)$ & $6,47(0,48)$ & $6,02(0,97)$ \\
\hline Taste $^{3}$ & $5,75(1,16)$ & $5,90(1,20)$ & $4,83(1,94)$ & $5,58(1,41)$ \\
\hline Health $^{3}$ & $4,25 \mathrm{a}(2,06)$ & $5,80 \mathrm{a}(1,14)$ & $6,83 \mathrm{~b}(0,41)$ & $5,80(1,47)$ \\
\hline Safety & $6,43 \mathrm{a}, \mathrm{b}(0,79)$ & $6,40 \mathrm{a}(0,70)$ & $7,00 \mathrm{~b}(0,00)$ & $6,57(0,66)$ \\
\hline Attractiveness & $6,13 a, b(0,83)$ & $5,50 \mathrm{a}(1,84)$ & $6,83 \mathrm{~b}(0,41)$ & $6,04(1,37)$ \\
\hline Environmental friendliness & $5,71 \mathrm{a}, \mathrm{b}(1,80)$ & $5,30 \mathrm{a}(1,77)$ & $6,83 \mathrm{~b}(0,41)$ & $5,83(1,61)$ \\
\hline Chain balance & 5,85b $(0,94)$ & $5,50 \mathrm{~b}(0,89)$ & $3,67 a(1,72)$ & $5,25(1,36)$ \\
\hline Distribution of risks and benefits & $5,89(1,17)$ & $5,00(1,15)$ & $5,33(2,25)$ & $5,40(1,47)$ \\
\hline Information exchange ${ }^{3}$ & $5,78 b(0,83)$ & $5,90 \mathrm{~b}(0,99)$ & $2,83 \mathrm{a}(1,47)$ & $5,12(1,67)$ \\
\hline Chain understanding & $5,89 \mathrm{~b}(1,05)$ & $5,60 a, b(1,17)$ & $3,40 \mathrm{a}(2,30)$ & $5,25(1,67)$ \\
\hline
\end{tabular}

${ }^{1}$ Seven-point Likert scale: 1 = strongly unimportant; $2=$ moderately unimportant; $3=$ slightly unimportant; $4=$ neutral; 5 = slightly important; $6=$ moderately important; $7=$ strongly important; different letters $(\mathrm{a}-\mathrm{b}-\mathrm{c})$ indicate significantly different average scores using Mann-Whitney U test

${ }^{2}$ Supply chain goals eliminated because of low average importance scores

${ }^{3}$ Performance indicators marked as "under consideration for being eliminated"

Quality: Two performance indicators of the goal quality are of medium importance. One is taste and the other is health. Taste is determined by the sweetness, mealiness and aroma of the products (Aramyan, 2007). As traditional food products have their special taste character, maintaining the original taste of the product is more important than improving the tastiness or to better meet the requirements of the consumers with regards to taste. Therefore, one can not say that a tastier product has better quality. As a result, the relevance of the item is judged to be less important and is removed. Health refers to the quality of the products being salubrious and nutritious (Aramyan, 2007). Obviously, performance indicator of health receives significantly lower scores in Belgium then in the other countries. This is explained by the fact that legal 
restrictions does not allow of promoting health claims of alcoholic beverages and by the recommendation for moderate consumption of them (Hasler, 2002).

Chain balance: Information-exchange refers to all kind of information transfer between two companies (Bagozzi, 1975, Schreyögg, 1996). The importance of the performance indicator information-exchange is significantly different between the Italian respondents and the respondents of the other two countries. From the notes of the interviewers, we can learn that, the performance indicator information-exchange and chain-understanding are perceived as overlapping items. Chain-understanding refers to the extent to which business partners understand each other's products and processes; roles and responsibilities (Bensaou and Venkatraman, 1995, Bensaou, 1997). As chain-understanding is a broader concept, it has been decided that information-exchange will be removed from the list.

\section{Conclusions and future research topics}

In the frame of our paper, we developed a supply chain performance measurement instrument for traditional food supply chains via a four-stage process, resulting in five supply chain goals and their respective performance indicators for the traditional food sector (Table 4).

Table 4: Supply chain goals and their performance indicators
\begin{tabular}{|l|}
\hline Traditionalism \\
\hline Authenticity \\
\hline Recipe authenticity \\
\hline Raw material authenticity \\
\hline Production process authenticity \\
\hline Gastronomic heritage \\
\hline Efficiency \\
\hline Distribution cost \\
\hline Profit \\
\hline Responsiveness \\
\hline Lead time \\
\hline Customer complaints \\
\hline Quality \\
\hline Safety \\
\hline Attractiveness \\
\hline Environmental friendliness \\
\hline Chain balance \\
\hline Distribution of risks and benefits \\
\hline Chain understanding \\
\hline
\end{tabular}

The four-stage approach is experienced being appropriate to realize the objectives of our research, namely developing a supply chain performance measurement instrument for the traditional food sector. Through focus groups and interviews supply chain goals are identified. The consolidation process, based on specificity and conflicting/divergent nature, results in supply chain goals. The latter are further specified into performance indicators based on the literature. Finally, a pilot study investigating the importance experienced by different stakeholders resulted in the selection of the key performance indicators.

The developed supply chain performance measurement instrument reveals to be a compromise between being sector specific (traditionalism) and generally applicable (efficiency, responsiveness, quality, chain balance) supply chain goals. This result responds to the gap experienced in previous research.

Future research should tackle two important aspects. First, the developed instrument should be tested on a quantitative scale in the traditional food sector and in other food and non-food 
sectors. In this way, a confirmation of the generated compromise in our research should obtain. Second, the supply chain performance should be confronted with the individual stakeholder performance in order to reveal whether or not a causal relationship between both exits. These findings might have important implications for both policy makers and the business community.

\section{Acknowledgments}

The authors are grateful for their partners in the - TRUEFOOD- "Traditional United Europe Food", Integrated Project financed by the European Commission under the 6th Framework Programme for RTD, Contract n. FOOD-CT-2006-016264. The information in this document reflects only the author's views and the Community is not liable for any use that may be made of the information contained therein. 
Annex 1: Overview of focus groups and in-depth interviews

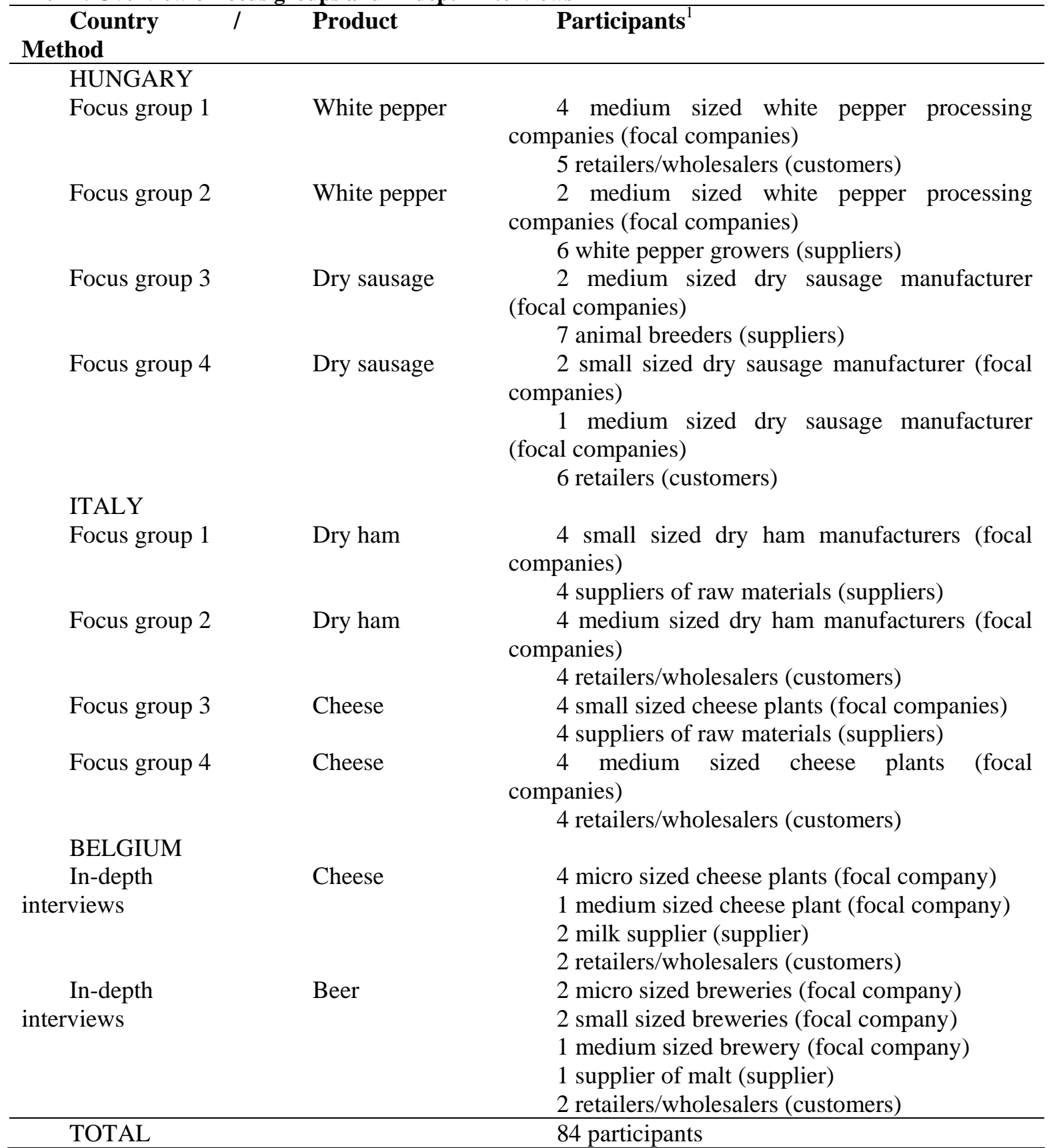

1 Micro sized enterprise: < 10 employees, maximum EUR 2 million annual turnover

Small sized enterprise: $>10$ and $<50$ employees, maximum EUR 10 million annual turnover

Medium sized enterprise: $>50$ and $<250$ employees, maximum EUR 50 million annual turnover 


\begin{tabular}{llcl}
\hline $\begin{array}{c}\text { Country } \\
\text { Method }\end{array}$ & $/$ & Product / Chain & Respondents $^{1}$ \\
\end{tabular}

\begin{tabular}{|c|c|c|}
\hline \multirow[t]{10}{*}{ BELGIUM } & Beer & \\
\hline & Chain 1 & 1 retailer/wholesaler (customer) \\
\hline & & 1 micro sized brewery (focal company) \\
\hline & & 1 supplier of raw materials (supplier) \\
\hline & Chain 2 & 1 retailer/wholesaler (customer) \\
\hline & & 1 small sized brewery (focal company) \\
\hline & & 1 supplier of raw materials (supplier) \\
\hline & Chain 3 & 1 retailer/wholesaler (customer) \\
\hline & & 1 medium sized brewery (focal company) \\
\hline & & 1 supplier of raw materials (supplier) \\
\hline \multirow[t]{7}{*}{ ITALY } & DRY HAM & \\
\hline & Chain 4 & 1 retailer (customer) \\
\hline & & $\begin{array}{l}1 \text { medium sized dry ham manufacturer (focal } \\
\text { company) }\end{array}$ \\
\hline & & 1 supplier of raw materials (supplier) \\
\hline & Chain 5 & 1 wholesaler (customer) \\
\hline & & $\begin{array}{l}1 \text { micro sized dry ham manufacturers (focal } \\
\text { company) }\end{array}$ \\
\hline & & 1 supplier of raw materials (supplier) \\
\hline \multirow[t]{11}{*}{ HUNGARY } & DRY & \\
\hline & SAUSAGE & \\
\hline & Chain 6 & 1 retailer (customer) \\
\hline & & $\begin{array}{l}1 \text { medium sized dry sausage manufacturer } \\
\text { (focal company) }\end{array}$ \\
\hline & & 1 supplier of raw material (supplier) \\
\hline & Chain 7 & 1 wholesaler (customer) \\
\hline & & $\begin{array}{l}1 \text { medium sized dry sausage manufacturer } \\
\text { (focal company) }\end{array}$ \\
\hline & & 1 supplier of raw materials (supplier) \\
\hline & Chain 8 & 1 retailer/wholesaler (customer) \\
\hline & & $\begin{array}{l}1 \text { small sized dry sausage manufacturer (focal } \\
\text { company) }\end{array}$ \\
\hline & & 2 supplier of raw materials (supplier) \\
\hline
\end{tabular}

Micro sized enterprise: $<10$ employees, maximum EUR 2 million annual turnover Small sized enterprise: $<50$ employees, maximum EUR 10 million annual turnover Medium sized enterprise: < 250 employees, maximum EUR 50 million annual turnover 


\section{References}

Aramyan, L. H., 2007. Measuring supply chain performance in the agri-food sector. Wageningen, Wageningen University 0-144.

Beamon, B. M., 1996a. Performance measures in supply chain management. In: Conference on Agile and Intelligent Manufacturing SystemsTroy, New York.

Beamon, B. M., 1996b. Performance measures in supply chain management. In: Institute, R. P. (editor) Proceedings of the 1996 Conference on Agile and Intelligent Manufacturing SystemsTroy, New York.

Beamon, B. M., 1998a. Supply chain design and analysis: Models and methods. International Journal of Production Economics, Vol. 55(3), 281-294.

Beamon, B. M., 1998b. Supply chain design and analysis:: Models and methods. International Journal of Production Economics, Vol. 55(3), 281-294.

Beamon, B. M., 1999. Measuring supply chain performance. International Journal of Operations \& Production Management, Vol. 19(3), 275-292.

Brosius, F., 2002. SPSS 11. Bonn, MITP-Verlag

Chen, I. J. and A. Paulraj, 2004. Understanding Supply Chain Management: Critical Research and a Theoretical Framework. International Journal of Production Research, Vol. 42(1), $131-163 \mathrm{p}$.

Christopher, M., 1998. Logistics and supply chain management : strategies for reducing cost and improving service. London, Financial times

Claro, D. P., G. Hagelaar and O. Omta, 2003. The determinants of relational governance and performance: How to manage business relationships? Industrial Marketing Management, Vol. 32(8), 703-716.

Cohen, S. and J. Roussel, 2005. Strategic Supply Chain Management. The five discipline for top performance, McGraw-Hill

Collins, A., M. Henchion and P. Reilly, 2001. Logistics customer service: performance of Irish food exporters. International Journal of Retail \& Distribution Management, Vol. 29, 6-15.

Cox, A., 1999. Power, value and supply chain management. Supply Chain Management: An International Journal Vol. 4(4), 167 - 175

Dransfield, S. B., N. I. Fisher and N. J. Vogel, 1999. Using Statistics and Statistical Thinking to Improve Organisational Performance. International Statistical Review / Revue Internationale de Statistique, Vol. 67(2), 99-122.

Felföldi, J., 2007. A zöldség termékpálya SWOT-mátrixa. In: Felföldi, J. and E. Szabó (editors). Ágazatspecifikus innováció alapuló projektek generálása a zöldség termékpályán. Debreceni Egyetem, Debrecen.

Fox, R., 2007. Reinventing the gastronomic identity of Croatian tourist destinations. International Journal of Hospitality Management, Vol. 26(3), 546-559.

Gellynck, X., B. Vermeire and J. Viaene, 2006. Innovation and networks in the food sector: Impact of regional factors. In: 99th EAAE Seminar on 'Trust and Risk in Business NetworksUniversity of Bonn, Germany, 143-154.

Giraud, G., 2002. Organic and origin-labeled food products in Europe: Labels for consumers or from producers? . In: Lockeretz, W. (editor) Ecolabels and the Greening of the Food Market. Tufts University, Boston, pp. 41-49. 
Gunasekaran, A., C. Patel and R. E. McGaughey, 2004. A framework for supply chain performance measurement. International Journal of Production Economics, Vol. 87(3), 333-347.

Gunasekaran, A., C. Patel and E. Tirtiroglu, 2001. Performance measures and metrics in a supply chain environment International Journal of Operations \& Production Management Vol. 21(1/2), 71-87.

Hasler, C. M., 2002. Functional Foods: Benefits, Concerns and Challenges--A Position Paper from the American Council on Science and Health. 132: 3772-3781.

Hines, P., R. Lamming, D. Jones, P. Cousins and N. Rich, 2000. Value Stream Management Financial Times Prentice Hall

Ittner, C. D. and D. F. Larcker, 2003. Coming Up Short on Nonfinancial Performance Measurement. Harvard Business Review, Vol. 81(11), 88-95.

Jordana, J., 2000. Traditional foods: challenges facing the European food industry. Food Research International, Vol. 33(3-4), 147-152.

Kaplan, R. S., 1983. Measuring Manufacturing Performance: A New Challenge for Managerial Accounting Research. Accounting Review, Vol. 58(4), 686.

Keeble, J. J., S. Topiol and S. Berkeley, 2003. Using Indicators to Measure Sustainability Performance at a Corporate and Project Level. Journal of Business Ethics, Vol. 44(2-3), 149-158 p. .

Lambert, D. M. and M. C. Cooper, 2000. Issues in Supply Chain Management. Industrial Marketing Management, Vol. 29(1), 65-83.

Lambert, D. M. and T. L. Pohlen, 2001. Supply Chain Metrics International Journal of Logistics Management, Vol. 12(1), 1-19.

Lee, H. L. and C. Billington, 1999. Managing supply chain inventory: pitfalls and opportunities. Sloan Management Review, Vol. 33, 65-73.

Li, D. and C. O'Brien, 1999. Integrated decision modelling of supply chain efficiency. International Journal of Production Economics, Vol. 59(1-3), 147-157.

Neely, A., M. Gregory and K. Platts, 1995. Performance measurement system design: A literature review and research agenda. International Journal of Operations \& Production Management, Vol. 15(4), 80-116.

Neely, A., J. Mills, K. Platts, M. Gregory and H. Richards, 1994. Realizing Strategy through Measurement. International Journal of Operations \& Production Management, Vol. 14(3), $140-152$.

Pearson, M. and A. Samali, 2005. Offsite Solution Delivery Centers Increasingly Important to High-performance Supply Chains. Outlook Point of View, Vol. January

Roos, G. and K. Jacobsen, 1999. Management in a complex stakeholder organization; a case study of the application of the IC-process to a branch of the commonwealth public service. Monash Mt. Eliza Business Review, Vol. 2, 1 p. .

Theodoras, D., L. Laios and M. Socrates, 2005. Improving customer service performance within a food supplier-retailer conext. International Journal of Retail \& Distribution Management, Vol. 33(5), 353-370.

Trichopoulou, A., E. Vasilopoulou, K. Georga, S. Soukara and V. Dilis, 2006. Traditional foods: Why and how to sustain them. Trends Food Sci Tech, Vol. 17, 498-504.

Van De Ven, A. H., 1976. A Framework For Organization Assessment. Academy of Management Review, Vol. 1(1), 64-78.

Van der Vorst, J., 2000. Effective food supply chains: generating, modeling and evaluating supply chain scenarios. Wageningen, Wageningen University 305 p. 
Van Der Vorst, J. G. A. J., 2006. Performance Measurement in Agri-Food Supply-Chain Networks, Logistics and Operations Research Group, Wageningen University 14-24.

Walsh, P., 1996. Finding key performance drivers: Some new tools. Total Quality Management, Vol. 7(5), 509-519.

Yamamoto, H., J. Fujino and K. Yamaji, 2001. Evaluation of bioenergy potential with a multiregional global-land-use-and-energy model. Biomass and Bioenergy, Vol. 21(3), 185-203.

Young, N. L., C. S. Bradely, V. Blanchette, C. D. Wakefield, D. Barnard, J. K. M. Wu and P. J. Mccusker, 2004. Development of a health-related quality of life measure for boys with haemophilia: the Canadian Haemophilia Outcomes - Kids Life Assessment Tool (CHOKLAT). Haemophilia, Vol. 10(1), 34-43. 